\title{
The Costs and Cost-Effectiveness of a District-Strengthening Strategy to Mitigate the 3 Delays to Quality Maternal Health Care: Results From Uganda and Zambia
}

\author{
Benjamin Johns, a Peter Hangoma, ${ }^{b}$ Lynn Atuyambe, ${ }^{c}$ Sophie Faye, ${ }^{a}$ Mark Tumwine, ${ }^{d}$ Collen Zulu, ${ }^{e}$ \\ Marta Levitt, ${ }^{\mathrm{f}}$ Tannia Tembo, ${ }^{\mathrm{g}}$ Jessica Healey, ${ }^{\mathrm{h}}$ Rui Li, ${ }^{\mathrm{i}}$ Christine Mugasha, ${ }^{\mathrm{i}}$ Florina Serbanescu ${ }^{\mathrm{i}}$ \\ and Claudia Morrissey Conlon, ${ }^{k}$ on behalf of the Saving Mothers, Giving Life Working Group
}

A comprehensive district-strengthening approach to address maternal and newborn health was estimated to cost US\$177 per life-year gained in Uganda and \$206 per life-year gained in Zambia. The approach represents a very cost-effective health investment compared to GDP per capita.

\section{ABSTRACT}

The primary objective of this study was to estimate the costs and the incremental cost-effectiveness of maternal and newborn care associated with the Saving Mothers, Giving Life (SMGL) initiative-a comprehensive district-strengthening approach addressing the 3 delays associated with maternal mortality-in Uganda and Zambia. To assess effectiveness, we used a before-after design comparing facility outcome data from 2012 (before) and 2016 (after). To estimate costs, we used unit costs collected from comparison districts in 2016 coupled with data on health services utilization from 2012 in SMGL-supported districts to estimate the costs before the start of SMGL. We collected data from health facilities, ministerial health offices, and implementing partners for the year 2016 in 2 SMGL-supported districts in each country and in 3 comparison non-SMGL districts (2 in Zambia, 1 in Uganda). Incremental costs for maternal and newborn health care per SMGL-supported district in 2016 was estimated to be US\$845,000 in Uganda and $\$ 760,000$ in Zambia. The incremental cost per delivery was estimated to be $\$ 38$ in Uganda and $\$ 95$ in Zambia. For the districts included in this study, SMGL maternal and newborn health activities were associated with approximately 164 deaths averted in Uganda and 121 deaths averted in Zambia in 2016 compared to 2012. In Uganda, the cost per death averted was $\$ 10,311$, or $\$ 177$ per life-year gained. In Zambia, the cost per death averted was $\$ 12,514$, or $\$ 206$ per life-year gained. The SMGL approach can be very cost-effective, with the cost per life-year gained as a percentage of the gross domestic product (GDP) being $25.6 \%$ and $16.4 \%$ in Uganda and Zambia, respectively. In terms of affordability, the SMGL approach could be paid for by increasing health spending from $7.3 \%$ to $7.5 \%$ of GDP in Uganda and from $5.4 \%$ to $5.8 \%$ in Zambia.

\section{INTRODUCTION}

ub-Saharan Africa has the highest lifetime risk of maternal mortality (1:36) of any region in the

\footnotetext{
a International Development Division, Abt Associates Inc., Bethesda, MD, USA.

${ }^{b}$ Department of Health Policy and Management, School of Public Health, University of Zambia, Lusaka, Zambia.

'Department of Community Health and Behavioral Sciences, School of Public Health, College of Health Sciences, Makerere University, Kampala, Uganda.

¿Uganda Country Office, U.S. Centers for Disease Control and Prevention, Entebbe, Uganda.

e U.S. Agency for International Development, Lusaka, Zambia.

' Bureau for Global Health, U.S. Agency for International Development, Washington, DC, USA, and RTI, Washington, DC, USA. Now with Palladium, Abuja, Nigeria. ${ }^{9}$ Centre for Infectious Disease Research in Zambia, Lusaka, Zambia.

hU.S. Agency for International Development, Lusaka, Zambia. Now based in Monrovia, Liberia.

'Division of Reproductive Health, U.S. Centers for Disease Control and Prevention, Atlanta, GA, USA.

iU.S. Agency for International Development, Kampala, Uganda.

k Bureau for Global Health, U.S. Agency for International Development, Washington, DC.

Correspondence to Benjamin Johns (ben_johns@abtassoc.com).
}

world. ${ }^{1,2}$ For example, the maternal mortality ratio in 2015 was 546 per 100,000 live births, with an estimated 201,000 maternal deaths. The maternal mortality ratio in sub-Saharan Africa is almost 22 times that in Europe. ${ }^{1,2}$ Studies have documented the financial, economic, and social consequences of maternal deaths, including increased risk of death for newborns and lower educational achievement, poorer economic outcomes, and poorer health for surviving children., ${ }^{3,4}$ Coverage of essential antenatal, maternal, and newborn health services remains below levels needed to reach internationally agreed upon goals. ${ }^{5}$ Despite these continuing challenges, the maternal mortality ratio declined in sub-Saharan Africa between 1990 and 2015 by $45 \%,{ }^{6}$ coinciding with the scale-up of essential antenatal, maternal, and newborn interventions.

Three health system barriers have long been known to delay timely access to quality obstetric and newborn 
care (the "3 delays"): (1) barriers in deciding to seek care at a health facility; (2) barriers in reaching a facility in time to receive the needed care; and (3) barriers in receiving high-quality, respectful, and timely care at the facility. ${ }^{7}$ To reduce these barriers, stakeholders may implement an integrated package of supply-side interventions, particularly health system strengthening activities to ensure quality care, and demand-side interventions within and outside the health facility setting to increase knowledge of, access to, and utilization of care. ${ }^{5,8}$

The significant costs to households and communities of a maternal death are well documented. ${ }^{3}$ Existing literature suggests that essential maternal health interventions are highly cost-effective. 9,10 For example, based on regional-level estimates from the World Health Organization's (WHO's) Choosing Interventions that are Cost-Effective (CHOICE) model, a full package of maternal care costs 36 International dollars (I\$) per disabilityadjusted life-year (DALY) averted in high disease burden countries in sub-Saharan Africa (compared to no maternal care). ${ }^{9}$ Similarly, according to the Bill and Melinda Gates Foundation-funded Disease Control Priorities project, emergency obstetric care costs US\$10 per DALY averted in low- and middleincome countries. ${ }^{10}$ Thus, the cost per DALY averted for maternal care appears to be well below the average gross domestic product (GDP) per capita in any country in the world. However, these studies focus primarily on improvements in clinical care, which is associated with the third delay. A review conducted by the Disease Control Priorities project also contains primarily interventions based in health facilities. ${ }^{11}$ The WHO-CHOICE model lists community-based interventions for antenatal and neonatal care "including outreach," but it does not specify what constitutes outreach. ${ }^{9}$

Other studies demonstrate the effectiveness of interventions to reduce one or more of the 3 delays, ${ }^{12-14}$ but the literature on the cost of these interventions is limited. A recent review of the costs of maternal care in low- and middle-income countries found 8 studies assessing the costs of antenatal care and 18 studies assessing the costs of delivery. ${ }^{15}$ Of these, only 1 study from sub-Saharan Africa included the costs of community-based maternal support. ${ }^{15}$ Further, existing literature on the costeffectiveness of maternal health interventions tends to focus on the additional costs and effectiveness of a single intervention ${ }^{16-20}$ that typically addresses only 1 of the 3 delays. A few cost-effectiveness studies include health systems strengthening as a complement to a demand generation intervention ${ }^{21}$ or assess the cost-effectiveness of a more comprehensive approach to improving coverage of skilled care at birth. ${ }^{22}$ Overall, however, the literature assessing the costs and cost-effectiveness of a comprehensive health systems strengthening approach to address all 3 delays is scarce. An exception is a cost-effectiveness analysis of maternal and newborn interventions in Uganda under Phase 1 of the Saving Mothers, Giving Life (SMGL) initiative, ${ }^{23}$ but this study did not account for the full costs of interventions, chiefly because indirect facility overheads were not considered.

The primary objectives of the current study were to estimate the costs and incremental costeffectiveness of maternal and newborn care associated with SMGL's comprehensive districtstrengthening approach to addressing the 3 delays in selected districts in Uganda and Zambia. Secondarily, we assessed the sources of financing for the SMGL interventions. Findings from our analyses can inform stakeholder investments on cost-effective means to reduce maternal and perinatal mortality.

\section{CONTEXT AND SMGL INTERVENTIONS}

Uganda and Zambia have very high maternal mortality levels, despite the occurrence of substantial reductions, including downward national trends before and during the period of SMGL implementation. ${ }^{24}$ The maternal mortality ratio in Zambia declined from 591 maternal deaths per 100,000 live births as measured in $2007^{25}$ to 398 per 100,000 live births as measured in $2013 .^{26}$ The maternal mortality ratio in Uganda declined from 432 maternal deaths per 100,000 live births as measured in $2011^{27}$ to 336 per 100,000 live births as measured in $2016 .^{28}$ The neonatal mortality rate in Uganda and Zambia in 2011-2013 was estimated to be 27 and 24 per 1,000 live births, respectively. ${ }^{26,28}$ In Uganda, $57 \%$ of women delivered in health facilities in 2011 , including $52 \%$ of women in rural areas. $^{27}$ In Zambia, about two-thirds of women delivered in health facilities in 2013; however, in rural areas, this percentage was $56 \%{ }^{26}$

Against this background, SMGL was implemented in 2012 in an effort to dramatically and rapidly reduce maternal mortality in selected districts of Uganda and Zambia (and later, Nigeria). The SMGL approach is based on context-specific solutions to maternal and, later, newborn health $(\mathrm{MNH})$ problems. These solutions are identified and implemented through a coalition of partners,

\author{
Three health \\ system barriers \\ have long been \\ known to delay \\ timely access to \\ quality obstetric \\ and newborn \\ care-the 3 delays \\ pertain to seeking \\ care at a health \\ facility, reaching a \\ facility in time, \\ and receiving \\ quality care once \\ there.
}

\section{The SMGL approach is based on context-specific solutions to maternal and newborn health problems.}


including governments, nongovernmental organizations, and the private sector. ${ }^{29}$ SMGL principles The estimated
costs of MNH
interventions were
assessed in
selected districts
where the SMGL
approach was
implemented and
compared to
estimated costs in
2012, prior to
SMGL

interventions.

include the following: tem in a given geographic area through formal assessment of both public and private sectors.

3. Addressing all 3 delays to care to ensure access a complication, focusing on the period of labor, delivery, and the 72 hours postpartum when women and newborns are most vulnerable. ${ }^{30}$
1. Understanding the maternal health ecosys-

2. Using scarce resources rationally to address gaps and improve access to and quality of care. to lifesaving care within 2 hours of the onset of

4. Decreasing missed opportunities by integrating MNH and HIV services.

5. Counting, analyzing, and reporting all maternal and newborn deaths, and using findings to improve care. ${ }^{24}$

With substantial subnational variation in maternal mortality ratios within these countries, SMGL targeted districts that had among the poorest maternal health indicators in each country. ${ }^{24}$ The districts selected in Uganda were Kabarole, Kamwenge, Kibaale, and Kyenjojo. In Zambia, the districts selected were Kalomo, Lundazi, Mansa, and Nyimba. ${ }^{24}$

In the first year of implementation, SMGL was associated with a $35 \%$ reduction in the institutional maternal mortality ratio across the 2 countries. ${ }^{7}$ Donor investment was planned to be largest in the first years of the SMGL initiative, with national and local governments assuming greater responsibility for SMGL costs over time. Table 1 lists the interventions and activities included in the costing estimates for Uganda and Zambia.

\section{METHODOLOGY}

\section{Study Design}

We calculated the costs per maternal death averted and life-year gained by combining data on intervention costs that we compiled with direct outcome evaluation data from studies that previously documented maternal and newborn mortality associated with the SMGL approach. Health impact data in the SMGL-supported districts were collected in a separate evaluation of SMGL. ${ }^{30,31}$ The impact evaluation used a before-after design comparing selected health indicators and outcomes in 2012 (baseline) and 2016 (endline). These evaluations, including the data sources and the impact results, are described elsewhere in this special supplement. ${ }^{30}$

The estimated costs of $\mathrm{MNH}$ interventions were assessed in a subset of the districts where the SMGL approach was implemented and compared to estimated costs in 2012, prior to SMGL interventions. Since costs were not directly collected in the SMGL-supported districts prior to SMGL implementation in 2012, we derived comparison costs from the 2016 unit costs (e.g., cost per antenatal care visit, cost per vaginal delivery, cost per cesarean delivery) in neighboring districts where MNH programs were chiefly supported by country government efforts alone, to be consistent with the time frame for the effectiveness evaluation (end year as 2016). Table 2 lists the variables used in the cost-effectiveness analysis, along with the sources of data.

Because cost data prior to SMGL implementation were not available, we assumed that SMGL would affect the unit cost of health services through both the scale (quantity utilized) and quality of services. ${ }^{32}$ Thus, we selected comparison districts in the costing analysis for proxy measures of costs before SMGL, assuming that the unit prices of health services in these districts were similar to those in the SMGL-supported districts prior to interventions. We also assumed that unit costs in the comparison districts did not change substantially during the 2012-2016 time period, and we conducted sensitivity analyses to explore this assumption. We used districts as the unit of analysis because the SMGL approach was implemented at the district level, and many of the costs were incurred at the district level and could not be easily attributed to specific health facilities. This study assessed costs associated with provision of MNH care retrospectively in the SMGL intervention districts for the year 2016, including annualized start-up costs and capital costs over the 2012-2016 period. Start-up costs are defined as the costs for activities needed to establish interventions that are not incurred on an annual basis, while capital costs include the purchase of durable goods that are used over multiple years. Thus, we assumed effects are not cumulative across years except to the extent that continued capacity building, which is captured in start-up costs, allowed for increasing the effectiveness of the SMGL approach over time. We also assessed unit costs in comparison districts for the year 2016. We then used these unit costs together with 2012 utilization data from SMGL intervention districts to estimate costs in 2012 in the SMGL-supported districts (before SMGL started). 
TABLE 1. Activities and Interventions Included in the Costing Estimates

Activity or Intervention

Implemented in Uganda, Zambia, or Both ${ }^{a}$

Activities targeting delay $1^{b}$

Train community groups (VHTs and SMAGs) to promote facility delivery and birth preparedness

Uganda and Zambia

Procure bicycles, equipment, and supplies for community groups

Provide financial support to community activities (e.g., funding to attend monthly meetings, supervision costs, community assessment mappings)

Produce a documentary about safe motherhood using traditional leaders

Uganda and Zambia

Run mass media campaigns on safe motherhood (including development of materials, air time costs, and translation costs), engage community drama groups

Identify and engage community change champions in safe motherhood

Uganda and Zambia

Provision of revolving Fund for Village Saving Schemes

Zambia

MNH outreach (project or community staff visits to communities)

Uganda and Zambia

Activities targeting delay $2^{b}$

Distribution of subsidized vouchers for transport to delivery in EmONC facilities, public and private (transport to antenatal and postnatal care were added in Phase 2)

Procurement of ambulances, motorcycles, and motorbikes for transportation and referrals

Zambia

District-level transport committees to improve referral

Uganda

Uganda and Zambia

Renovate MWHs near hospitals for high-risk women

Train MWH staff to operate maternity homes; costs and revenue from income-generating activities; provision of food for those in maternity homes (as applicable)

Activities targeting delay $3^{b}$

Provide antenatal care

Uganda and Zambia

Provide basic delivery care

Uganda and Zambia

Provision of comprehensive emergency care (blood transfusion/cesarean delivery)

Uganda and Zambia

Upgrade care in neonatal special care units, including purchase of equipment, training, and provision of

Uganda and Zambia essential medicines

Increase facility EmONC capacity, including purchase of EmONC equipment and provision of essential medicines

Uganda and Zambia

Establish/expand/refurbish maternity blocks, neonatal special care units, laboratories, pharmacies, and operating theaters

Hire new doctors, nurses, and midwives

Uganda and Zambia

Train health workers in essential newborn care and neonatal resuscitation

Train doctors in surgical obstetric care and nurses in anesthesia, train/mentor nurses in basic EmONC

Other training and mentoring (e.g., rapid syphilis screening, PMTCT, essential newborn care, UBT, maternal and perinatal death reviews)

Supervision of frontline workers to maintain/improve skills in obstetrics/newborn care

Provide essential medicines

Provide training and oversight for maternal death reviews

Uganda and Zambia, primarily Uganda

Uganda and Zambia

Uganda and Zambia

Uganda and Zambia;

UBT in Zambia

Uganda and Zambia

Uganda and Zambia

Uganda and Zambia

Conduct health facility assessments

Uganda and Zambia

Continued 
TABLE 1. Continued

Activity or Intervention

Implemented in Uganda, Zambia, or Both ${ }^{a}$

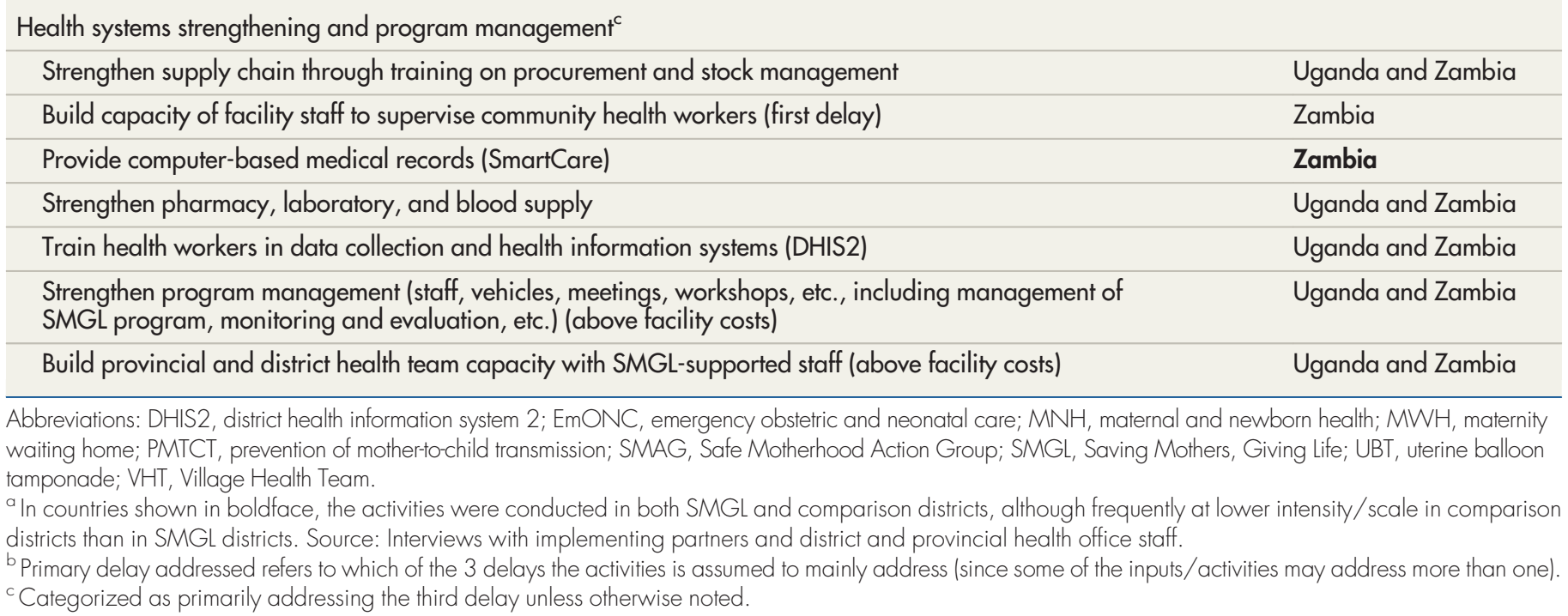

\section{Selection of Study Areas}

Planned data collection included 2 of the 4 learning districts in each country. In Zambia, we randomly selected Mansa and Nyimba from the 4 SMGLsupported districts for inclusion in these analyses. Mansa became 2 separate districts (Mansa and Chembe) in 2012, and data were collected from both. We also selected 2 districts, Kapiri Mposhi and Mbala, for comparative purposes for the costing analyses. The intent was to conduct the costing study in districts used in an external evaluation of SMGL at the end of Phase 1, where 2 comparison districts were selected to be similar to SMGL-supported districts across a number of factors (including health infrastructure, geography and climate, health utilization, morbidity and mortality, and socioeconomic context) that would also likely influence costs. ${ }^{29}$ However, one of the comparison districts (Kabwe) later received extensive donor support for $\mathrm{MNH}$ programs and was excluded. We decided to select a second comparison district from the Northern Province. We randomly selected Mbala district after excluding districts participating in the World Bank's resultsbased financing project in the province.

In Uganda, we purposively included the greater Kibaale district (now existing as 3 districts; data were collected from all 3 districts) in the study because it was the only SMGL district to receive extensive support from one of the 2 main implementing partners.
From the other 3 SMGL-supported districts, we selected Kyenjojo as the remaining rural district with a district hospital. Both districts received similar SMGL-supported interventions, with the exception of transport vouchers, which were implemented in Kyenjojo only. ${ }^{33}$ We also included the Fort Portal Referral Hospital, which received referrals from both Kibaale and Kyenjojo (and is located in a third SMGL district). For comparison purposes, we selected Masindi district, which served as a comparison district in an early evaluation of SMGL because it is located in the Western region and has a population and health system similar to the SMGLsupported districts. Due to limited time and budget, only one comparison district was included in Uganda.

In each of the selected districts of Uganda and Zambia, we collected data from the district health office, the government hospital in that district, and 2 randomly selected government health centers. Overall, we collected data from 5 districts, 4 hospitals, and 6 health centers in Uganda ( 3 health centers level III and 3 health centers level IV-one of each type in each of 2 SMGL-supported districts and in the comparison district), and 5 districts, 4 hospitals, and 8 health centers in Zambia. Data relating to $\mathrm{MNH}$ care activities in these districts were collected from district and provincial health offices (where appropriate) at the national level and from implementing partners, including 3 implementing 
Table 2. Parameters Used to Calculate District Costs of MNH Care, Life-Years Lost Due to Maternal Death, and Incremental Cost-Effectiveness of Deaths Averted

\begin{tabular}{llcll}
\hline Number & Parameter & Value & Data Source & Notes \\
\hline Costs (all) & & & & \\
\hline 1 & Discount rate & $3 \%$ & WHO-CHOICE recommendation ${ }^{34}$ & $\begin{array}{l}\text { Locally published discount rates used in } \\
\text { sensitivity analysis (15\% in Uganda and } \\
9.7 \% \text { in Zambia) }\end{array}$ \\
\end{tabular}

\section{Costs 2012}

$2 \begin{array}{ll}\text { Costs associated } \\ \text { with the first delay }\end{array} \quad \begin{aligned} & \text { Varies by district } \\ & \text { (see Table 4) }\end{aligned}$
with the first delay (see Table 4)

Costs associated
$\begin{aligned} & \text { with the second } \\ & \text { delay }\end{aligned}$

4 Unit cost of ANC $\begin{aligned} & \text { Varies by type of } \\ & \text { facility (see Table 3) }\end{aligned}$

$5 \quad$ Number of ANC visits

6

$9 \quad$ Number of cesarean Varies by district deliveries

$\begin{array}{ll}\text { Unit cost of vaginal } & \begin{array}{l}\text { Varies by type of } \\ \text { delivery }\end{array} \\ \text { facility (see Table 3) }\end{array}$

Number of vaginal Varies by district deliveries

$\begin{array}{lll}\text { Above community/ } & \begin{array}{l}\text { Varies by district } \\ \text { facility costs }\end{array} & \text { (see Table 4) }\end{array}$

11

$$
\text { Total costs of } \mathrm{MNH} \quad \text { Calculation }
$$
care in 2012

Costs 2016

\begin{tabular}{|c|c|c|}
\hline 12 & $\begin{array}{l}\text { Costs associated } \\
\text { with the first delay }\end{array}$ & $\begin{array}{l}\text { Varies by district } \\
\text { (see Table 4) }\end{array}$ \\
\hline 13 & $\begin{array}{l}\text { Costs associated } \\
\text { with the second } \\
\text { delay }\end{array}$ & $\begin{array}{l}\text { Varies by district } \\
\text { (see Table 4) }\end{array}$ \\
\hline
\end{tabular}

Interviews with health facility staff, district Interviews covered the period 2012 health office staff, provincial health office through 2016; start-up activities and staff, and implementing partners in comparison districts capital costs were tracked. Costs for existing maternity waiting homes are included.

Interviews with health facility staff, district Interviews covered the period 2012 health office staff, provincial health office through 2016; start-up activities and staff, implementing partners, and review capital costs were tracked. of ambulance log books in comparison districts

Data collection at health facilities in comparison districts, interviews with implementing partners

Ratio of ANC visits to Data from health facility registers/district Number of facility births based on health offices in comparison districts SMGL districts data from 2012

Data collection at health facilities in comparison districts, interviews with Inclusive of facility overhead costs and implementing partners admissions (for mother and newborn)

Data from health facility registers/district Number for SMGL districts in 2012 health offices in comparison districts, Serbanescu and colleagues ${ }^{30}$

Data collection at health facilities in comparison districts, interviews with implementing partners

Inclusive of facility overhead costs and admissions (for mother and newborn)

Data from health facility registers/district Number for SMGL districts in 2012 health offices in comparison districts, Serbanescu and colleagues ${ }^{30}$

Interviews with health facility staff, district Interviews covered the period 2012 health office staff, provincial health office through 2016; start-up activities and staff, and implementing partners in com- capital costs were tracked. parison districts

Based on parameters 2-10

Interviews with health facility staff, district Interviews covered the period 2012 health office staff, provincial health office through 2016; start-up activities and staff, and implementing partners in SMGL districts capital costs tracked. Costs for maternity waiting homes are included.

Interviews with health facility staff, district Interviews covered the period 2012 health office staff, provincial health office through 2016; start-up activities and staff, implementing partners, and review of ambulance log books in SMGL districts 
Table 2. Continued

\begin{tabular}{|c|c|c|c|c|}
\hline Number & Parameter & Value & Data Source & Notes \\
\hline 14 & Unit cost of ANC & $\begin{array}{l}\text { Varies by type of } \\
\text { facility (see Table 3) }\end{array}$ & $\begin{array}{l}\text { Data collection at health facilities in } \\
\text { SMGL districts, interviews with imple- } \\
\text { menting partners }\end{array}$ & Inclusive of facility overhead costs \\
\hline 15 & $\begin{array}{l}\text { Number of ANC } \\
\text { visits }\end{array}$ & $\begin{array}{l}\text { Ratio of ANC visits to } \\
\text { number of facility } \\
\text { births }\end{array}$ & $\begin{array}{l}\text { Data from health facility registers/district } \\
\text { health offices in SMGL districts }\end{array}$ & $\begin{array}{l}\text { Number of facility births based on } \\
\text { SMGL districts data from } 2016\end{array}$ \\
\hline 17 & $\begin{array}{l}\text { Number of vaginal } \\
\text { deliveries }\end{array}$ & Varies by district & Serbanescu and colleagues ${ }^{30}$ & Number for SMGL districts in 2016 \\
\hline 18 & $\begin{array}{l}\text { Unit cost of cesarean } \\
\text { delivery }\end{array}$ & $\begin{array}{l}\text { Varies by type of } \\
\text { facility (see Table 3) }\end{array}$ & $\begin{array}{l}\text { Data collection at health facilities in } \\
\text { SMGL districts, interviews with imple- } \\
\text { menting partners }\end{array}$ & $\begin{array}{l}\text { Inclusive of facility overhead costs and } \\
\text { admissions (for mother and newborn) }\end{array}$ \\
\hline 20 & $\begin{array}{l}\text { Above community/ } \\
\text { facility costs }\end{array}$ & $\begin{array}{l}\text { Varies by district } \\
\text { (see Table 4) }\end{array}$ & $\begin{array}{l}\text { Interviews with health facility staff, district } \\
\text { health office staff, provincial health office } \\
\text { staff, and implementing partners in com- } \\
\text { parison districts }\end{array}$ & $\begin{array}{l}\text { Interviews covered the period } 2012 \\
\text { through 2016; start-up activities and } \\
\text { capital costs were tracked. }\end{array}$ \\
\hline 21 & $\begin{array}{l}\text { Total costs of MNH } \\
\text { care in } 2016\end{array}$ & Calculation & Based on parameters $12-20$ & $\begin{array}{l}\text { In Uganda, included cost of patients } \\
\text { referred to Fort Portal referral hospital }\end{array}$ \\
\hline \multicolumn{5}{|c|}{ Deaths in 2012} \\
\hline 22 & $\begin{array}{l}\text { Number of facility- } \\
\text { based deliveries }\end{array}$ & Varies by district & $\begin{array}{l}\text { POMS and unpublished district data, } \\
\text { district offices in SMGL districts }\end{array}$ & $\begin{array}{l}\text { Number of deliveries for SMGL districts } \\
\text { in } 2016 \text { multiplied by the institutional } \\
\text { delivery rate in } 2012\end{array}$ \\
\hline 25 & $\begin{array}{l}\text { Number of maternal } \\
\text { deaths }\end{array}$ & Calculation & $\begin{array}{l}\text { Parameter } 22 \times \text { proportion of deliveries } \\
\text { with live births } / 100,000 \times \text { Parameter } 23\end{array}$ & \\
\hline 26 & $\begin{array}{l}\text { Number of perinatal } \\
\text { deaths }\end{array}$ & Calculation & Parameter 22/1,000 × Parameter 24 & \\
\hline 27 & $\begin{array}{l}\text { Total number of } \\
\text { deaths }\end{array}$ & Calculation & Parameter 25 + Parameter 26 & \\
\hline 28 & $\begin{array}{l}\text { Life-years lost due to } \\
\text { death }\end{array}$ & $\begin{array}{l}\text { Years of life left esti- } \\
\text { mated as } 62.5 \text { and } \\
45.6 \text { for perinatal } \\
\text { and maternal death } \\
\text { in Uganda and } 62.3 \\
\text { and } 45.7 \text { for perina- } \\
\text { tal and maternal } \\
\text { death in Zambia }\end{array}$ & WHO life tables ${ }^{40,41}$ & $\begin{array}{l}\text { Assume average age at death for } \\
\text { maternal death is } 27.5 \text {, for perinatal in } \\
\text { first } 2 \text { days of life }\end{array}$ \\
\hline
\end{tabular}


Table 2. Continued

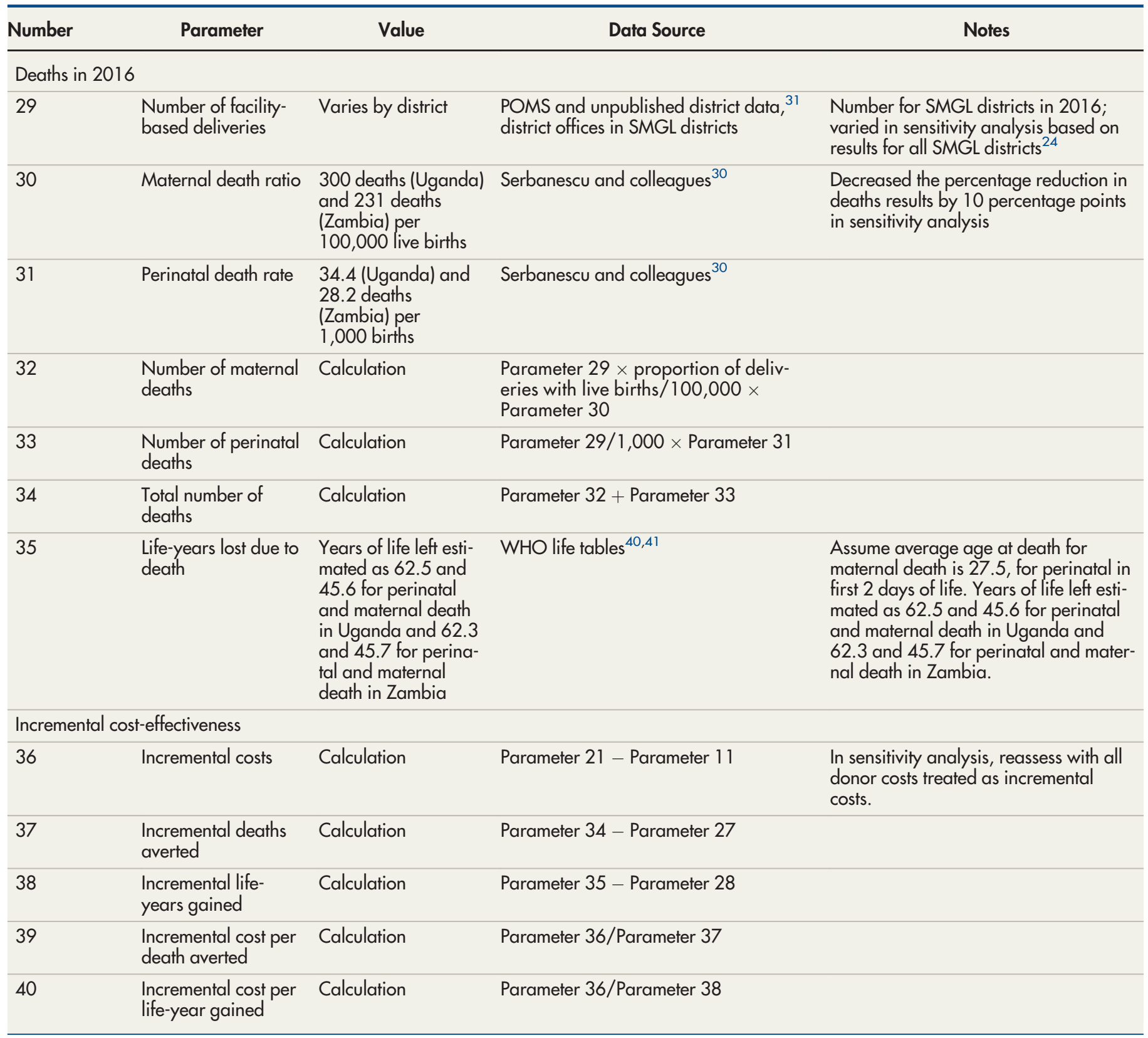

Abbreviations: ANC, antenatal care; MNH, maternal and newborn health; POMS, Pregnancy Outcome Monitoring Survey; SMGL, Saving Mothers, Giving Life; WHO CHOICE, World Health Organization's Choosing Interventions that are Cost-Effective.

partners in Uganda and over 30 in Zambia involved in $\mathrm{MNH}$ care, in the districts included in this analysis.

\section{Ethical Approval}

The data collection specific to this study was exempted from the need for ethical approval by Abt Associates Institutional Review Board and from the University of Zambia Biomedical
Research Ethics Committee in July 2017 because it did not include research on human subjects. The study received approval from the Makerere University of Public Health Higher Degrees, Research, and Ethics Committee in January 2018 and the Uganda National Council for Science and Technology (approval number SS 4511 ) in February 2018. 


\section{Data Collection}

Data collection at health facilities occurred in July-August 2017 in Zambia and FebruaryMarch 2018 in Uganda. Trained data collection teams extracted information on health facility area (square meters), staffing, service utilization, vehicles, and consumption of commodities from these facilities. Data were entered into Microsoft Excel templates designed for the study and were reviewed daily by data collection supervisors and again by the research team. Questions were sent to data collectors to verify information, and facilities were contacted again to clarify ambiguous information as needed. Similarly, structured templates were used to capture data at district health offices and, where appropriate, provincial health offices related to overall district health statistics (e.g., number of deliveries, number of health facilities) and activities related to $\mathrm{MNH}$ (e.g., training, health systems strengthening, mentoring, supervision, community outreach) during 2012-2016 for annualized start-up costs.

Data collection templates were constructed based on past analyses of expenditures in SMGL $\operatorname{areas}^{34,35}$ and sent to implementing partners. Data collectors then visited these partners to provide support for extracting the necessary data. Implementing partners provided data on all relevant start-up activity costs, capital expenditures, and routine activities for 2012-2016. Costs for national-level activities were not included unless the activity specifically focused on one of the districts included in these analyses; thus, for example, these analyses did not include costs for international staff and national staff working on multiple projects in addition to SMGL or costs for offices outside the SMGL districts.

Data were collected for all activities supporting $\mathrm{MNH}$, whether or not they were "officially" part of SMGL. However, some activities were not assessed as part of the SMGL evaluation, including HIV/AIDS care or prevention for pregnant women and postpartum family planning outside the $\mathrm{MNH}$ clinics of health facilities, unless the SMGL program specifically included them.

\section{Data Analysis Methods}

We used a 1-year analytic horizon for deaths averted (i.e., the difference between deaths occurring in 2012 and in 2016) and a lifetime analytic horizon for life-years gained. We included costs from the health system perspective-that is, costs incurred by the health system and implementing partners. Costs incurred by patients and volunteers' time were not captured or included in the analysis. Capital items and start-up costs were converted into annual equivalent costs using standard formulas; we assumed a 3\% discount rate $^{36}$ but explored locally published discount rates in sensitivity analyses. ${ }^{37,38}$ All costs were inflated to 2016 based on local GDP inflators and are presented in US dollars. ${ }^{39}$

We used a financial approach to estimate the costs of activities presented in Table 1. Costs of activities targeting communities included the support of volunteer community groups (Village Health Teams in Uganda and Safe Motherhood Action Groups in Zambia), including costs to train, equip, and organize group meetings.

We employed a mix of top-down and bottomup costing methods to estimate health facility costs. ${ }^{40}$ Costs of administrative and support services (e.g., cleaning, maintenance) were allocated to maternal, newborn, and antenatal wards or clinics based on number of staff, size, number of prescriptions, or service utilization in a top-down manner. Costs for ambulances were allocated to $\mathrm{MNH}$ services based on a review of ambulance logs. Whenever possible, quantities of consumables used directly in provision of maternal and newborn care were estimated from existing registers and stock cards specifying the amounts issued to a ward or clinic. If these data were not available, we relied on either allocation based on utilization (for general drugs and supplies) or health facility staff opinion (for drugs used specifically for maternal health). Quantities of consumables were multiplied by their unit prices, which were collected at the national level. Staff costs, inclusive of salary and benefits, were allocated to $\mathrm{MNH}$ services based on assigned duty stations, opening hours, work patterns, and service utilization. In Uganda, costs for utilities and building costs in public facilities were estimated based on implementing partners' accounts of costs for similar items; in Zambia, costs for utilities and buildings were estimated from previous costing exercises (R Homan, FHI 360, written communication, January 2018). Almost $40 \%$ of delivering facilities in Uganda SMGL-supported districts and 9\% in Zambia are private. ${ }^{30}$ Costs for maternal and newborn services at nongovernmental health facilities in Uganda were based on a previous study carried out in the same districts. ${ }^{41}$ Costs incurred at health facilities and reported by implementing partners were cross-checked to ensure that items were not double counted.

Total costs for MNH services for entire districts were estimated using the average unit costs from 
sampled facilities for different types of services (e.g., antenatal care, vaginal delivery, cesarean delivery) and multiplying the results by the total utilization of these services in a district. These figures include costs for inpatient admissions. For estimates of costs before the start of SMGL, we used utilization numbers from the SMGLsupported districts in 2012 and unit costs from comparison districts, while for 2016 we used utilization numbers and unit costs from SMGLsupported districts in 2016. We disaggregated these calculations by type of health facility. We then added costs incurred at the community level and "above service delivery costs" (e.g., costs for offices located in districts, general and office support staff, program vehicles, and other general management and planning activities) to the facility-based costs. For SMGL districts, the programmatic costs and facility costs to address the first, second, and third delay total costs were added to derive the total costs for the districts. To convert costs incurred outside health facilities in comparison districts to costs incurred in 2012, we divided these costs by the number of facility deliveries in the comparison districts and then multiplied the results by the number of facility deliveries estimated to have occurred without SMGL in the SMGL districts. This calculation assumes that costs outside facilities varied directly with the number of deliveries at facilities; however, costs outside facilities in the comparison districts were a small proportion of all costs. For the 2012 cost estimates, we included observed community-level and above service delivery level costs from the comparison districts, under the assumption that these activities also likely existed in SMGL-supported districts before the start of SMGL. We calculated costs per facility delivery in districts in the absence of SMGL, we started with the number of deliveries for SMGL districts in 2016 multiplied by the institutional delivery rate in 2012 to estimate the number of facility-based deliveries that would have occurred without SMGL. To account for secular trends in maternal mortality and perinatal deaths, we adjusted the facility-based maternal mortality ratios and perinatal death rates from 2012 by subtracting the change in these indicators at a national level from 2012 to 2016 from the SMGL districtspecific 2012 figures (see Supplement 1). 27,28,42,43 To reflect a generalizable cost-effectiveness applicable as broadly as possible, we used the facilitybased death ratios/rates from all SMGL areas. However, since we collected costs in only half of the SMGL-supported districts, this approach assumes that costs in the districts included in the costing data collection did not differ substantially from those in the SMGL-supported districts where cost data were not collected. We subsequently explored this assumption in a sensitivity analysis (described below).

The number of deaths averted was estimated by subtracting the number of deaths in 2012 from the number of deaths in 2016. We estimated the incremental cost-effectiveness by dividing the incremental costs by the number of deaths averted in SMGL areas. Additionally, we estimated the potential remaining years of life for pregnant women and newborns at the time of death and calculated the cost per life-year gained using national life-expectancy data. ${ }^{44,45}$ For averted perinatal deaths, we calculated the cost per lifeyear gained assuming that stillborn infants and newborns would have had a full life expectancy. ${ }^{46}$

\section{Sensitivity Analyses} 2012 (i.e., baseline facility delivery costs) and in 2016 (defined as the costs of improved facility delivery, which included all costs associated with delivery, demand generation, and transport). Incremental costs were calculated by taking the difference between the estimated total costs in 2016 and those in 2012. Sources of financing (donor, government, and private) were tracked throughout this exercise.

To estimate the health impact, we used the facility-based maternal mortality ratios and perinatal death rates in 2016 in SMGL-supported districts multiplied by the reported number of facility-based deliveries for the cohort of women giving birth in 2016 to determine the number of deaths in $2016 .^{31}$ To estimate the number of deaths that would have occurred in the same

We conducted sensitivity analyses to explore the potential impact of our assumptions on the results. Sensitivity analyses were done by changing input variable amounts and assessing how results were altered. The following scenarios and variables were considered for sensitivity analyses:

1. We used locally published discount rates to calculate annual equivalent costs.

2. We re-estimated the increased number of deliveries at health facilities using data from all 4 SMGL-supported districts rather than the 2 districts included in the costing. Chance variation in the increase in the number of deliveries at health facilities between districts may change the results.

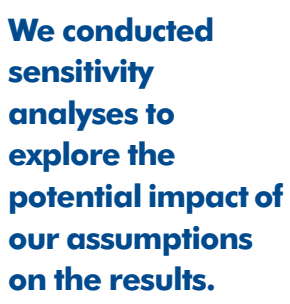

Global Health: Science and Practice 2019 | Volume 7 | Supplement 1 
3. We re-estimated the proportion of facility deliveries by cesarean delivery, for the same reason as above and using the same method.

4. We re-estimated incremental costs by considering all donor-supported costs as incremental costs (as opposed to using estimated 2012 costs). Although donor funds may displace some other sources of funding, this provides an upper-end estimation of the incremental costs in the absence of other district data.

5. We re-estimated the cost of preventing a year of lost life considering a discount rate of $3 \%$ for future life-years, as suggested by the WHO-CHOICE guidance. ${ }^{36}$

Applying each of these 5 scenarios, we also calculated a "combined-case" scenario in which all the above scenarios were included at the least favorable value. Finally, we re-ran the analyses using mortality rates/ratios specific to the 2 SMGL-supported districts included in the costing.

\section{RESULTS}

\section{Unit Costs}

Average unit costs of a vaginal delivery in facilities in SMGL districts were lower or comparable to costs in facilities in non-SMGL districts in Uganda in 2016 (Table 3). The opposite is true for Zambia, where average unit costs were generally higher in facilities in SMGL districts. Specifically, in Uganda facility-based cost (excluding training of staff) for a vaginal delivery ranged from $\$ 24$ to $\$ 45$ across types of facilities in districts where SMGL was implemented, compared to $\$ 25$ to $\$ 57$ across types of facilities in the comparison district. In Zambia, the cost of a vaginal delivery was \$42 at health centers and \$1 18 at hospitals (on average across types of hospitals) in districts where SMGL was implemented, compared to $\$ 18$ and $\$ 56$, respectively, in comparison districts.

Similarly, cesarean delivery unit costs in Uganda were lower in health centers (\$202) in SMGL districts than in health centers in the comparison district (\$337). However, the costs were

TABLE 3. Average Unit Cost of Selected Services at Health Facilities in 2016

\begin{tabular}{|c|c|c|c|c|}
\hline & \multicolumn{2}{|c|}{ Uganda } & \multicolumn{2}{|c|}{ Zambia } \\
\hline & SMGL-Supported Districts & Comparison District & SMGL-Supported Districts & Comparison Districts \\
\hline \multicolumn{5}{|l|}{ Vaginal delivery } \\
\hline Health center III & $\$ 41$ & $\$ 42$ & & \\
\hline Health center IV & $\$ 45$ & $\$ 57$ & & \\
\hline Health center & & & $\$ 42$ & $\$ 18$ \\
\hline District/general hospital & $\$ 26$ & $\$ 25$ & $\$ 12$ & $\$ 28$ \\
\hline Referral hospital & $\$ 24$ & Not available & $\$ 125$ & $\$ 112$ \\
\hline \multicolumn{5}{|l|}{ Cesarean delivery } \\
\hline Health center IV & $\$ 202$ & $\$ 337$ & & \\
\hline District/general hospital & $\$ 163$ & $\$ 140$ & $\$ 33$ & $\$ 616$ \\
\hline Referral hospital & $\$ 79$ & Not available & $\$ 495$ & $\$ 458$ \\
\hline \multicolumn{5}{|l|}{ Antenatal care visit } \\
\hline Health center III & $\$ 3.66$ & $\$ 5.49$ & & \\
\hline Health center IV & $\$ 3.59$ & $\$ 5.07$ & & \\
\hline Health center & & & $\$ 4.50$ & $\$ 3.96$ \\
\hline District/general hospital & $\$ 5.03$ & $\$ 4.60$ & $\$ 6.96$ & $\$ 10.75$ \\
\hline Referral hospital & $\$ 4.92$ & Not available & $\$ 38.90$ & Not available \\
\hline
\end{tabular}

Abbreviations: SGML, Saving Mothers, Giving Life.

Notes: The table includes only costs incurred at the facility level; it does not include training of facility staff. Results are presented in US 2016 dollars inclusive of capital and facility overhead costs. Data were not collected from the referral hospital receiving cases from Masindi. 
higher in Uganda hospitals (\$163) in SMGL districts than in hospitals $(\$ 140)$ in the comparison district. At the referral hospital in an SMGL district, the cost of a cesarean delivery was $\$ 79$ because the operating theater had a relatively high volume of services. In Zambia, the average cesarean delivery unit costs were lower in hospitals ( $\$ 468$ on average across types of hospitals) in SMGL districts compared to hospitals (\$508) in comparison districts.

Average unit costs of an antenatal care visit were lower in health centers $(\$ 3.66$ for level III and $\$ 3.59$ for level IV) in SMGL districts than in health centers (\$5.49 for level III and \$5.07 for level IV) in the comparison district in Uganda. In contrast, hospitals in SMGL districts had higher average unit costs $(\$ 5.03)$ compared to hospitals (\$4.60) in the comparison district for an antenatal visit. The cost structure in Zambia was different; health centers in SMGL districts had higher average unit costs of an antenatal care visit (\$4.50) than facilities (\$3.96) in comparison districts, while there were mixed results from the comparison of SMGL hospitals and non-SMGL hospitals.

\section{Total Costs}

In 2012 in Uganda, total costs for MNH care were estimated to be about $\$ 650,000$ per district, or almost $\$ 66$ per facility delivery, while total costs for MNH care in Zambia in 2012 were estimated to be just under $\$ 425,000$ per district or about $\$ 101$ per facility delivery. Total costs for $\mathrm{MNH}$ care per district for the year 2016 were approximately \$1.5 million in SMGL-supported districts in Uganda and almost \$1.2 million in Zambia (Table 4). This translates to approximately \$104 per "improved facility delivery" in Uganda and \$196 per improved facility delivery in Zambia.

TABLE 4. Total Costs Per District and Sources of Financing

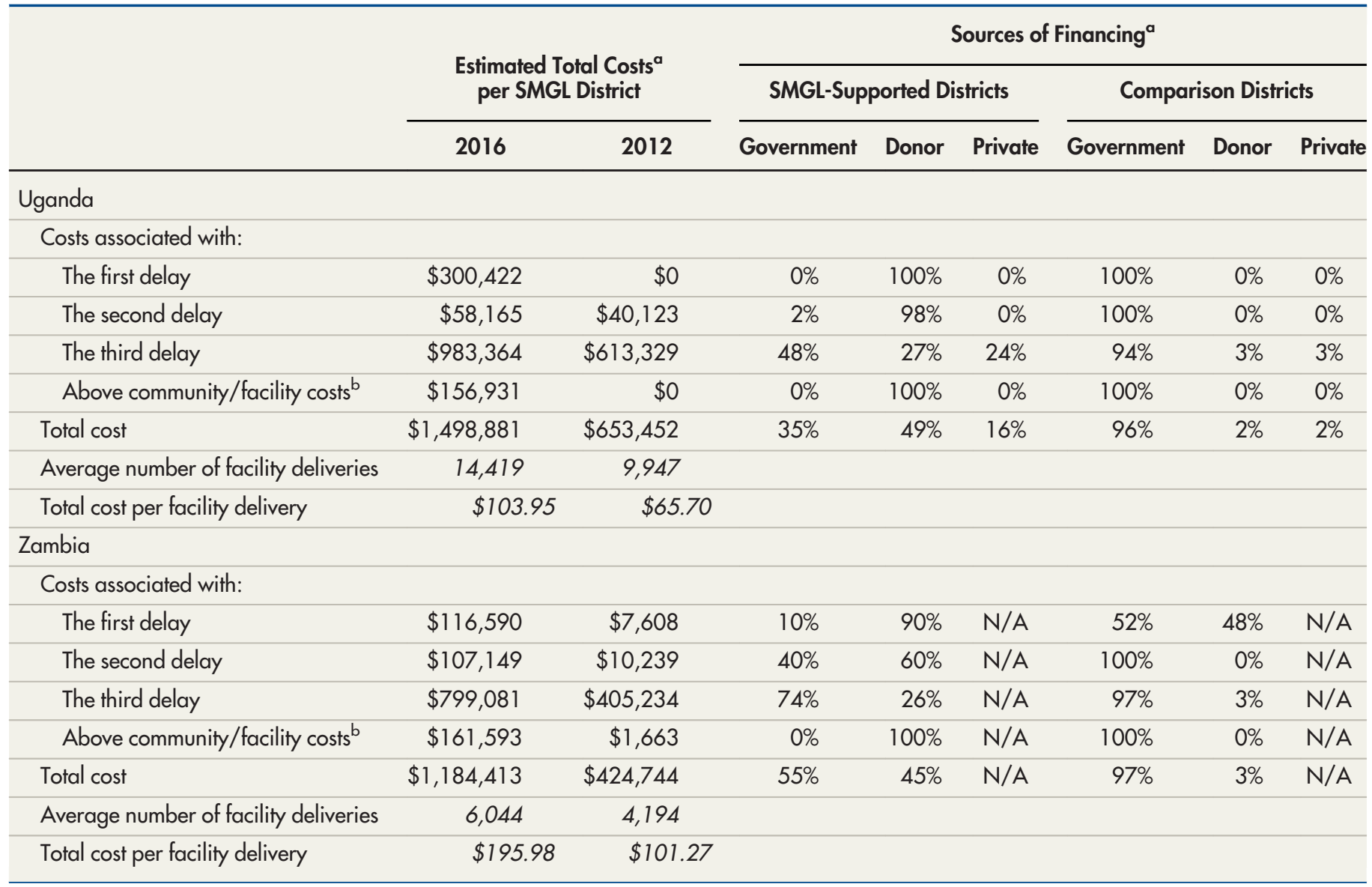

Abbreviations: N/A, not applicable; SMGL, Saving Mothers, Giving Life.

a Results are presented in US 2016 dollars, with capital and start-up costs converted to annual equivalent costs.

b Includes costs for offices located in districts, general and office support staff, program vehicles, and other general management and planning activities. 
Donors supported the majority of costs associated with the first and second delays and just under $30 \%$ of costs related to the third delay in both countries in SMGLsupported districts.
In 2016, donors covered about $49 \%$ of the $\mathrm{MNH}$ costs in Uganda and $45 \%$ of costs in Zambia in the SMGL-supported districts. In comparison districts, donors covered $2 \%$ (Uganda) and $3 \%$ (Zambia) of all costs in 2016. Costs incurred at private facilities accounted for $16 \%$ of costs in SMGL-supported districts in Uganda (although we were not able to assess the amount of donor financial support for births at private facilities). Donors supported the majority of costs associated with the first and second delays and just under $30 \%$ of costs related to the third delay in SMGLsupported districts.

\section{Incremental Costs}

In Uganda, the cost per facility delivery in 2016 in the SMGL-supported index districts was \$38 higher than in 2012 . Over $35 \%$ of the incremental cost went to support activities addressing the first delay, about $44 \%$ was spent on issues related to the third delay, $2 \%$ was spent on issues related to the second delay, and the remainder was spent on above community/facility costs for program support.

Similarly, the cost per facility delivery in Zambia in SMGL-supported districts was about $\$ 95$ more in 2016 than in 2012. Addressing the first delay accounted for about $14 \%$ of the incremental cost, and above community/facility costs for program support were associated with approximately $21 \%$ of the incremental cost per facility delivery. About $52 \%$ of the incremental cost in SMGL-supported districts in Zambia addressed the third delay.

\section{Incremental Effects}

In Uganda SMGL areas, the institutional maternal mortality ratio was 534 deaths per 100,000 live births in 2012 and 300 in 2016 . The institutional perinatal morality rate was 39.3 per 1,000 births in 2012 and 34.4 in 2016 in SMGL areas. The percentage of deliveries in facilities changed from $45.5 \%$ in 2012 to $66.8 \%$ in 2016 , and the population cesarean delivery rate increased from $5.3 \%$ to $9.0 \% .^{30}$

In Zambia SMGL areas, the institutional maternal mortality ratio declined from 370 deaths to 231 deaths per 100,000 live births and the institutional perinatal morality rate declined from 37.9 to 28.2 deaths per 1,000 births from 2012 to 2016 . The percentage of deliveries in facilities increased from $62.6 \%$ to $90.2 \%$ and the population cesarean delivery rate increased from $2.7 \%$ to $4.8 \%$. $^{30}$

\section{Incremental Cost-Effectiveness Ratios}

Based on the number of facility deliveries in the 4 districts included in this analysis, scale-up of $\mathrm{MNH}$ activities is associated with averting 164 deaths in

TABLE 5. Incremental Cost-Effectiveness of SMGL in Uganda and Zambia

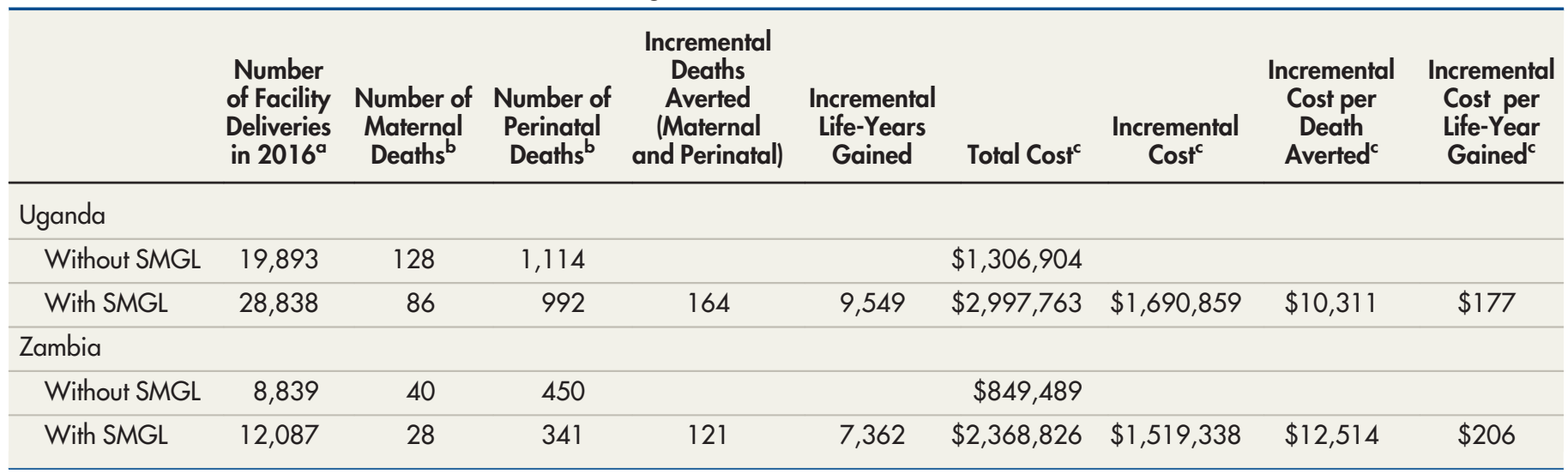

Abbreviation: SGML, Saving Mothers, Giving Life.

"The number of district deliveries in 2016 multiplied by the institutional delivery rate for 2012 (for "without SMGL") and for 2016 (for "with SMGL") reported in Serbanescu et al. ${ }^{30}$

b Estimated using the 2016 facility deliveries with SMGL (for both "with SMGL" and "without SMGL") and the total maternal/perinatal death rates for all SMGLsupported districts in 2016 (for with SMGL) and $2012^{30}$ with adjustments for national-level secular trends (see Supplement 1) to estimate deaths if SMGL had never occurred (for without SMGL)

${ }^{c}$ Results are presented in US 2016 dollars, and represent the totals for the 2 SMGL-supported districts included in the analyses. 
FIGURE 1. Results of Sensitivity Analysis for Uganda and Zambia

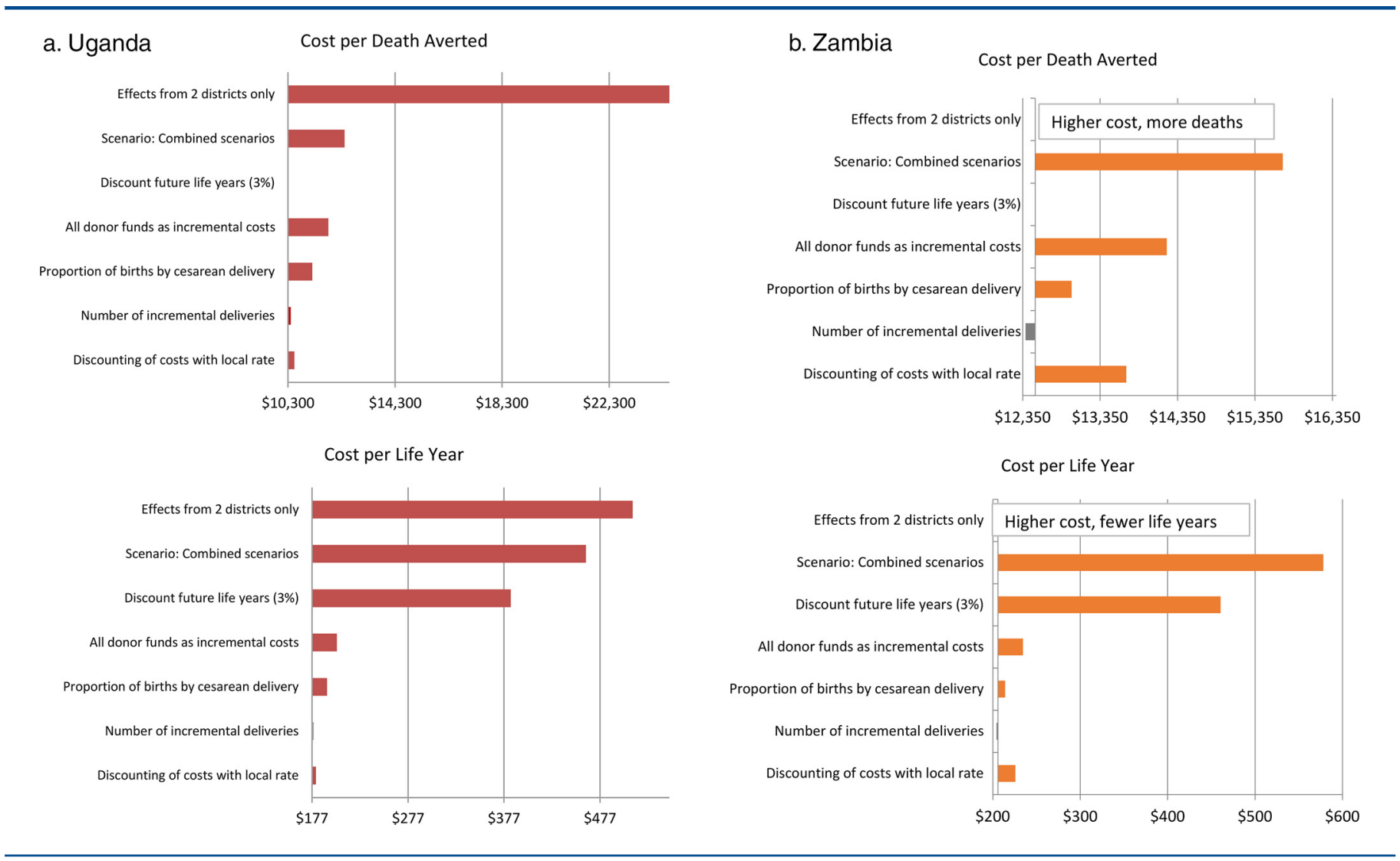

Uganda and 121 deaths in Zambia in the 2 SMGLsupported districts in 2016 included in this analysis (Table 5). This translates to 9,549 years of life gained in Uganda and 7,362 years of life gained in Zambia. In Uganda, the incremental costs were estimated to be about $\$ 1,690,859$, or $\$ 10,311$ per death averted and $\$ 177$ per life-year gained. With an estimated incremental cost of $\$ 1,519,338$ in Zambia in 2016, the incremental cost per death averted was $\$ 12,514$, or $\$ 206$ per life-year gained.

\section{Sensitivity Analyses}

Figure la and Figure lb depict for Uganda and Zambia, respectively, the cost per death averted or the cost per life-year gained along the $\mathrm{x}$-axis, with each bar representing the change in the incremental cost-effectiveness ratio associated with changing an assumption. In Uganda, including effects only from Kibaale and Kyenjojo districts would result in a cost per death averted of about $\$ 25,550$, with a cost per life-year gained of about \$511 (Figure 1a). In Zambia, while the overall SMGL program was associated with reductions in mortality, using data from only Mansa and Nyimba resulted in a higher cost and reverse mortality effect (Figure 1b). This outcome was due to higher facility-based maternal and perinatal death rates in Mansa district in 2016 than in 2012, which were greater than the lower deaths rates in Nyimba district. The mortality increase in Mansa was largely due to more adverse outcomes that occurred in the referral hospital in Mansa in 2016, which provided delivery care to SMGL districts and to 5 additional non-SMGL-supported districts as well.

In Uganda and Zambia, results related to the cost per death averted were otherwise most sensitive to assumptions about using all donor costs as incremental costs. For any given scenario, the cost per death averted remained less than $\$ 12,000$ in Uganda and \$14,300 in Zambia. In a scenario combining the 5 main sensitivity analyses, where all assumptions were moved to the least favorable cost-effectiveness scenario, the cost per death averted was around $\$ 12,411$ in 
Uganda and \$15,708 in Zambia. The cost per lifeyear saved was most sensitive to the assumption about whether to discount future life-years. When future life-years were discounted, the cost per lifeyear gained increased to \$384 in Uganda and $\$ 460$ in Zambia. In the scenario combining the 5 main sensitivity analyses, the cost per life-year gained was \$462 in Uganda and \$578 in Zambia.

In the 4 SMGLsupported districts included in these analyses, scale-up of MNH interventions prevented an estimated 285 institutional maternal and perinatal deaths in 2016.

We found that the
incremental cost
per life-year
gained was
$\$ 177$ in Uganda
and $\$ 206$ in
Zambia.

\section{DISCUSSION}

In the 4 SMGL-supported districts included in these analyses, scale-up of $\mathrm{MNH}$ interventions prevented an estimated 285 institutional maternal and perinatal deaths in 2016 , or about 71 death per district per year (0.6 death averted per $100 \mathrm{fa}$ cility deliveries in Uganda and 1.0 death averted per 100 facility deliveries in Zambia). GDP per capita is a commonly used benchmark to determine whether or not an intervention is highly costeffective, with the cost per DALY averted below the GDP per capita used as the benchmark for being highly cost-effective. ${ }^{36}$ The assessments of SMGL did not track changes in morbidity, and, to the extent that scale-up of $\mathrm{MNH}$ interventions prevented or ameliorated morbidity, our use of life-years gained likely underestimated the effects (as compared to DALYs averted).

Nevertheless, we found that the incremental cost per life-year gained in Uganda was \$177, or $25.6 \%$ of the GDP per capita of $\$ 692$, and the incremental cost per life-year gained in Zambia was $\$ 206$, which is $16.4 \%$ of the GDP per capita of $\$ 1,257$.

A previous study assessing SMGL activities in Uganda suggested an incremental cost ranging from \$28 to \$104 per improved delivery, depending upon which activities were included in the costs, compared with our finding of about $\$ 38$ per facility delivery. ${ }^{23}$ Another study assessing a maternal voucher scheme in Uganda, however, found that it cost about $\$ 340$ per DALY averted, a higher ratio than we found here. ${ }^{21}$ However, only one district in our study promoted maternal vouchers, while a second had only $24 \%$ of facility deliveries supported by vouchers in $2016 .^{33}$ Another study assessing surgical interventions for maternal health found a cost per DALY averted ranging from $\$ 7$ to $\$ 360$, depending on the procedure. ${ }^{47}$ Overall, the cost per life-year gained estimated here tends to be higher than the cost per DALY averted found in global models, but is similar to or lower than the cost per DALY averted from assessments of specific interventions in Uganda.
While recent estimates of unit costs of $\mathrm{MNH}$ activities are not available in Zambia, the unit costs found in this study are on the higher end of unit costs from other studies in Uganda. For example, a recent review found the cost of antenatal care in Uganda was about $\$ 5.90$ at health centers and $\$ 6.40$ at hospitals per woman, ${ }^{15}$ only marginally more than our estimated cost per antenatal care visit in Uganda. The same review also found that the cost per vaginal delivery in a facility in Uganda ranged from $\$ 5$ to $\$ 46$ across studies (compared with $\$ 24$ to $\$ 45$ in SMGL-supported districts and $\$ 25$ to $\$ 57$ in comparison districts documented here). The cost per cesarean delivery ranged from \$61 to \$108 (compared with \$31 to $\$ 202$ in SMGL-supported districts and \$140 to $\$ 337$ in comparison districts documented here). ${ }^{15}$ These findings suggest that the costs we estimated in our study are similar to or higher than those reported previously, at least for Uganda.

We did not see a marked change across the board in unit costs of services between SMGLsupported districts and comparison districts when we included only costs incurred at health facilities. In many cases, unit costs were lower in SMGLsupported districts. This was likely because of higher patient volumes in SMGL-supported facilities, with the increased efficiency in the use of capital and overhead costs offsetting the costs of increasing the quality of services. The exception was for vaginal delivery in Zambia, where unit costs were mostly higher in SMGL-supported districts than in comparison districts, but also where there was less difference in the number of deliveries between 2012 and 2016 than in Uganda. When we included costs incurred outside health facilities, including training, mentoring, and community mobilization-that is, the cost of an improved facility delivery-the cost per facility delivery in SMGL-supported districts was substantively higher than in comparison districts.

Funding for reducing the first delay constituted $36 \%$ of incremental costs in Uganda and $14 \%$ of incremental costs in Zambia, representing $20 \%$ and $10 \%$ of total costs in SMGL-supported districts, respectively. In comparison districts, the cost of activities addressing the first delay was either nonexistent (Uganda) or marginal (\$1.81 per facility delivery in Zambia). Costs for the activities addressing the second delay were $4 \%$ and $9 \%$ of total costs in SMGL-supported districts in Uganda and Zambia, respectively. While funding for the second delay was similar in the SMGL-supported and comparison districts in Uganda (transportation vouchers were not implemented in Kibaale, 
and used only on a limited basis in 2016 in Kyenjojo), it was substantially higher in Zambia, where costs for maternity homes were a main cost driver for the second delay. For each facility delivery, \$17.73 was spent on activities addressing the second delay in Zambia SMGL-supported districts, contrasting with $\$ 2.44$ in comparison districts. The increase in costs per facility delivery was less marked (in percentage terms) for activities addressing the third delay, possibly representing either efficiencies, as noted above, or displacement of other funds. In terms of the total incremental costs, the third delay used the highest amount of resources in Uganda (about \$370,000 per district) and in Zambia (about \$394,000 per district). However, the results suggest that spending about $20 \%$ to $25 \%$ of $\mathrm{MNH}$ budgets to address the first 2 delays-critical delays that can prevent women from accessing care in a timely way-can be enough to improve receipt of timely facility care at birth. While securing and ensuring funding for activities to address the first 2 delays is critical, the results also suggest that in Uganda and Zambia, funding for facility deliveries was inadequate in 2012 to provide sufficient quantity and quality of care, with donors supporting more than $25 \%$ of costs addressing the third delay in SMGL districts in both Uganda and Zambia in 2016.

This study is limited by use of comparison districts that were assessed only at the end of the SMGL program. These districts serve as an imperfect proxy estimate of the cost of $\mathrm{MNH}$ services before the start of the SMGL program. In addition, use of before and after data to estimate the effects of the scale-up of MNH services is subject to confounding due to secular trends. Although we tried to account for secular trends using national data, the national trends may not have been realized in the SMGL districts over the same time period.

Because data from 2016 in comparison areas were used as proxies for unit costs in SMGLsupported districts in 2012, we assessed data from 2016 in comparison districts with data from SMGLsupported districts in 2012 to ensure comparability. In Uganda, there were about 700 births per facility in SMGL-supported districts in 2012 and 500 births per facility in comparison districts in 2016, while in Zambia, there were about 225 births per facility in both 2012 in SMGL-supported districts and 2016 in comparison districts. In Uganda, 6\% of facility births were by cesarean delivery in the SMGL-supported districts in 2012, compared with $9 \%$ in comparison districts in 2016, while in Zambia the percentage of facility births by cesarean delivery was $7 \%$ and $3 \%$, respectively.
Because data from comparison districts suggest a close match with intervention districts before the start of SMGL in some cases but a notable difference in other instances, we addressed potential biases in sensitivity analyses by using available data on likely ranges for changes in facilitybased deliveries, cesarean deliveries, and incremental costs per facility delivery. In all cases, conclusions did not change substantively.

However, the effects presented here could potentially be underestimates for several reasons. Assessing progress in reducing facility maternal and perinatal mortality during the initiative required using facility data and data abstraction protocols. In 2012, each country faced the immediate challenge of how to produce baseline measurements of maternal and perinatal mortality in the period immediately before the initiative began and comparable measurements during the initiative, when data quality improvements were institutionalized. At baseline, each country used its existing data systems and infrastructure to devise its own independent data-collection approach. Although the definitions of indicators were standard, the quality of primary data used to calculate the number of maternal and perinatal deaths was substantially lower at baseline than at endline in both countries. In addition, differences in data collection existed between Uganda and Zambia. Thus, some deaths were likely missed in the baseline count, which would bias our results downward. Further, the proportion of deliveries in facilities increased over time, but we applied the facility-based death ratios/rates to all births. To the extent that women who would have given birth at home without SMGL would have worse outcomes than were observed for facility births, we underestimate the effects of the program.

Lacking data, we have not tried to incorporate these effects into the analyses. Further, the complete effects of the program, which may include increasing staff morale and their ability to deliver other interventions (such as family planning or prevention/elimination of mother-tochild transmission of HIV), were not captured in the effect estimates. While we did not assess changes in patient payments to access services, we also did not include the potential cost savings (from productivity losses and other social costs) resulting from preventing a maternal or newborn death. 3,48

Donors spent upwards of $\$ 733,000$ per district in Uganda and \$538,000 per district in Zambia in total annual equivalent costs, and in the first year of SMGL \$2 million and \$1.5 per district in real

\section{The results suggest that spending about $20 \%$ to $25 \%$ of MNH budgets to address the first 2 delays can be enough to improve receipt of timely facility care at birth.}


The SMGL project could be paid for by increasing health spending from the $7.3 \%$ of GDP in 2015 (in Uganda) and $5.4 \%$ (in Zambia) to $7.5 \%$ and $5.8 \%$ of GDP, respectively. budgetary expenditures. These findings are in keeping with a previous study assessing SMGL expenditures (the data from these studies were reviewed as part of these analyses). ${ }^{34,35}$ Recent global estimates suggest that \$11 or more per capita per year in added costs are needed in subSaharan Africa to meet the full needs of MNH, sexual, and reproductive health care. ${ }^{49}$ While not achieving the full $80 \%$ mortality reductions suggested by the \$11 per capita figure and including a different set of interventions, the incremental annual costs of the project represent about $\$ 1.36$ per person living in the SMGL-supported districts in Uganda and $\$ 4.85$ per person in Zambia. Thus, the SMGL project could be paid for by increasing health spending from $7.3 \%$ of GDP in 2015 (in Uganda) and $5.4 \%$ (in Zambia) to $7.5 \%$ and $5.8 \%$ of GDP, respectively. ${ }^{44,45}$ Further, SMGL used an accelerated and capital-intensive model in Uganda and Zambia. Excluding capital and start-up costs, the donor financing for recurrent costs in 2016 was about $\$ 645,000$ per district in Uganda and $\$ 135,000$ per district in Zambia-just over $\$ 1$ per person in Uganda districts and about $\$ 0.86$ per person in Zambia districts. The SMGL project utilized program implementation staff located in the SMGL-supported districts, the costs of which are included here. However, if the model is replicated, the cost structures the governments may use would possibly be different from those used by implementing partners, or some duplication of efforts may possibly be reduced. Thus, the $10 \%$ to $14 \%$ of costs represented by above service delivery and community costs could be reduced when the program is replicated. Further work assessing the future financial implications and budgetary impact of continuing SMGL (or implementing SMGL in other districts or countries) is needed.

While the results from Uganda and Zambia were similar in terms of their cost-effectiveness, the sensitivity analyses looking at results only for districts with cost data indicate that heterogeneity would certainly exist in applying the results to other settings and within countries themselves. SMGL was targeted to areas within Uganda and Zambia with high maternal mortality, with some activities tailored to each district. Similar targeted approaches are likely necessary in other settings, which may affect the costeffectiveness in any particular setting. Further, the costs presented here do not account for potential changes to costs structures, demand for services, and average unit costs over time. In the future, increased uptake of family planning, further increases in demand for and use of services, and so forth will likely change the unit costs of delivering MNH services as well as the mix of activities needed. Thus, the cost-effectiveness of district health strengthening approaches such as SMGL will likely also change over time.

This study adds to the literature by presenting actual costs and effects of a health systems strengthening approach that addressed the $3 \mathrm{key}$ barriers to receiving $\mathrm{MNH}$ care. We find that the approach costs about $\$ 177$ to $\$ 206$ per year of life gained, depending on the context. Ministries of Health and donor agencies have already demonstrated a willingness to pay this amount per year of life gained; for example, first-line antiretroviral therapy cost over $\$ 200$ per person per year across 5 countries (including Zambia) in sub-Saharan Africa in $2010 .^{50}$ Thus, we conclude that the SMGL approach as demonstrated likely represents a very cost-effective health investment.

Acknowledgments: Thousands of individuals participated in activities to implement the Saving Mothers, Giving Life (SMGL) initiative. We would like to thank the many respondents that provided data for this study, including staff at health facilities, health offices and ministries, and implementing partners. This work would not have been possible without their gracious cooperation. Frank Kaharuza at USAID/Uganda also provided valuable insight into the SMGL program. Agnes GatomeMunyua, Kelley Ambrose, and Christopher Cintron of Abt Associates contributed to the development of the data collection tools and data analyses. Christine Muhumuza and Agnes Nyabigambo helped to review the cost data from Uganda.

Funding: Saving Mothers, Giving Life implementation was primarily funded by the Office of the Global AIDS Coordinator, USAID, Washington, DC; US Centers for Disease Control and Prevention, Atlanta, Georgia (Cooperative agreements GPS003057 and GPS002918); Merck for Mothers; and Every Mother Counts. This study was funded by USAID through the Health Finance and Governance Project (Cooperative Agreement No: AID-OAA-A-1200080). The funding agencies had no influence or control over the content of this article.

Disclaimer: The authors' views expressed in this publication do not necessarily reflect the views of the United States Government.

Competing Interests: None declared.

\section{REFERENCES}

1. Alkema L, Chou D, Hogan D, et al; United Nations Maternal Mortality Estimation Inter-Agency Group collaborators and technical advisory group. Global, regional, and national levels and trends in maternal mortality between 1990 and 2015, with scenario-based projections to 2030: a systematic analysis by the UN Maternal Mortality Estimation Inter-Agency Group. Lancet. 2016;387 (10017):462-474. CrossRef. Medline

2. Lifetime risk of maternal death. World Bank Open Data website. https://data.worldbank.org/indicator/SH.MMR.RISK. Accessed September 15, 2018.

3. Miller S, Belizán JM. The true cost of maternal death: individual tragedy impacts family, community and nations. Reprod Health. 2015;12(1):56. CrossRef. Medline 
4. Kirigia JM, Mwabu GM, Orem JN, Muthuri RDK. Indirect cost of maternal deaths in the WHO African Region in 2010. BMC Pregnancy Childbirth. 2014;14(1):299. CrossRef. Medline

5. Countdown to 2030 Collaboration. Countdown to 2030: tracking progress towards universal coverage for reproductive, maternal, newborn, and child health. Lancet. 2018;391(10129):P15381548. CrossRef. Medline

6. Black RE, Laxminarayan R, Temmerman M, Walker N. Reproductive, maternal, newborn, and child health. In: Disease Control Priorities. 3rd ed. Vol. 2. Washington, DC: World Bank; 2016.

7. Serbanescu F, Goldberg HI, Danel I, et al. Rapid reduction of maternal mortality in Uganda and Zambia through the saving mothers, giving life initiative: results of year 1 evaluation. BMC Pregnancy Childbirth. 2017;17(1):42. CrossRef. Medline

8. Koblinsky M, Moyer CA, Calvert C, et al. Quality maternity care for every woman, everywhere: a call to action. Lancet. 2016;388 (10057):2307-2320. CrossRef. Medline

9. Adam T, Lim SS, Mehta S, et al. Cost effectiveness analysis of strategies for maternal and neonatal health in developing countries. BM. 2005;331(7525):1107. CrossRef. Medline

10. Horton S, Gelband H, Jamison D, Levin C, Nugent R, Watkins D Ranking 93 health interventions for low- and middle-income countries by cost-effectiveness. PLoS One. 2017;12(8):e0182951. CrossRef. Medline

11. Gülmezoglu AM, Lawrie TA, Hezelgrave N, et al. Interventions to reduce maternal and newborn morbidity and mortality. In: Black RE, Laxminarayan R, Temmerman M, Walker N, eds. Reproductive, Maternal, Newborn, and Child Health. Vol 2. Washington, DC: World Bank; 2016:115-136.

12. Banu M, Akter M, Begum K, Choudhury RH, Nasreen HE. 'The clock keeps ticking' - the role of a community-based intervention in reducing delays in seeking emergency obstetric care in rural Bangladesh: a quasi-experimental study. Public Health. 2014;128(4):332-340. CrossRef. Medline

13. Erim DO, Resch SC, Goldie SJ. Assessing health and economic outcomes of interventions to reduce pregnancy-related mortality in Nigeria. BMC Public Health. 2012;12(1):786. CrossRef. Medline

14. Goldie SJ, Sweet S, Carvalho N, Natchu UCM, Hu D. Alternative strategies to reduce maternal mortality in India: a cost-effectiveness analysis. PLoS Med. 2010;7(4):e1000264. CrossRef. Medline

15. Levin C, Brouwer E. Saving Brains: literature review of reproductive, neonatal, child and maternal health and nutrition interventions to mitigate basic risk factors to promote child development. GCC Working Paper Series, GCC 14-08. http://repository.upenn.edu/ gcc_economic_returns/17/. Accessed February 19, 2019

16. Colbourn T, Pulkki-Brännström AM, Nambiar B, et al. Cost-effectiveness and affordability of community mobilisation through women's groups and quality improvement in health facilities (MaiKhanda trial) in Malawi. Cost EffResour Alloc. 2015;13(1):1. CrossRef. Medline

17. Lewycka S, Mwansambo C, Rosato M, et al. Effect of women's groups and volunteer peer counselling on rates of mortality, morbidity, and health behaviours in mothers and children in rural Malawi (MaiMwana): a factorial, cluster-randomised controlled trial. Lancet. 2013;381(9879):1721-1735. CrossRef. Medline

18. Mayora C, Ekirapa-Kiracho E, Bishai D, Peters DH, Okui O, Baine S Incremental cost of increasing access to maternal health care services: perspectives from a demand and supply side intervention in Eastern Uganda. Cost EffResour Alloc. 2014;12(1):14. CrossRef. Medline

19. Sabin LL, Knapp AB, MacLeod WB, et al. Costs and cost-effectiveness of training traditional birth attendants to reduce neonatal mortality in the Lufwanyama Neonatal Survival study (LUNESP). PLoS One. 2012;7(4):e35560. CrossRef. Medline
20. Somigliana E, Sabino A, Nkurunziza R, et al. Ambulance service within a comprehensive intervention for reproductive health in remote settings: a cost-effective intervention. Trop Med Int Health. $2011 ; 16(9): 1151-1158$. CrossRef. Medline

21. Alfonso YN, Bishai D, Bua J, Mutebi A, Mayora C, Ekirapa-Kiracho E. Cost-effectiveness analysis of a voucher scheme combined with obstetrical quality improvements: quasi experimental results from Uganda. Health Policy Plan. 2015;30(1):88-99. CrossRef. Medline

22. Newlands D, Yugbare-Belemsaga D, Ternent L, Hounton $S$, Chapman G. Assessing the costs and cost-effectiveness of a Skilled Care Initiative in rural Burkina Faso. Trop Med Int Health. 2008;13 (Suppl 1):61-67. CrossRef. Medline

23. Saving Mothers, Giving Life Phase 1 in Uganda: cost effectiveness analysis. USAID/Uganda Monitoring, Evaluation and Learning Program. 2016

24. Conlon CM, Serbanescu F, Marum L, et al; Saving Mothers, Giving Life Working Group. Saving Mothers, Giving Life: it takes a system to save a mother. Glob Health Sci Pract. 2019;7(Suppl 1):S6-S26. CrossRef

25. Central Statistical Office (CSO), Ministry of Health (MOH), Tropical Diseases Research Centre (TDRC), University of Zambia, Macro International Inc. Zambia Demographic and Health Survey 2007. Calverton, Maryland, USA: CSO and Macro International Inc.; 2009.

26. Central Statistical Office (CSO) [Zambia], Ministry of Health (MOH) [Zambia], ICF International. Zambia Demographic and Health Survey 2013-14. Rockville, Maryland, USA: Central Statistical Office, Ministry of Health, and ICF International; 2014.

27. Uganda Bureau of Statistics (UBOS), ICF International Inc. Uganda Demographic and Health Survey 2011. Kampala, Uganda and Calverton, Maryland: UBOS and ICF International Inc.; 2012.

28. Uganda Bureau of Statistics (UBOS), ICF International. Uganda Demographic and Health Survey 2016: Key Indicators Report. Kampala, Uganda, and Rockville, Maryland: UBOS and ICF; 2017.

29. Kruk ME, Galea S, Grépin K, et al. External evaluation of saving mothers, giving life: final report. New York, NY: Columbia University Mailman School of Public Health; 2013.

30. Serbansecu F, Clark TA, Goodwin M, et al; Saving Mothers, Giving Life Working Group. Impact of the Saving Mothers, Giving Life approach on decreasing maternal and perinatal deaths in Uganda and Zambia. Glob Health Sci Pract. 2019;7(Suppl 1):S27-S47. CrossRef

31. Pregnancy Outcome Monitoring Survey, Uganda and Zambia Facility Outcomes. Unpublished data, 2018.

32. Victora CG, Walker D, Johns B, Bryce J. Evaluations of large-scale health programs. In: Merson MH, Black RE, Mills AJ, eds. Global Health: Diseases, Programs, Systems, and Policies. 3rd ed. Burlington, MA: Jones \& Bartlett Learning; 2012:815-852.

33. Serbanescu F, Goodwin MM, Binzen S, et al; Saving Mothers, Giving Life Working Group. Addressing the First Delay in Saving Mothers, Giving Life districts in Uganda and Zambia: approaches and results for increasing demand for facility delivery services. Glob Health Sci Pract. 2019;7(Suppl 1):S48-S67. CrossRef

34. Futures Group. Expenditure Analysis for Saving Mothers, Giving Life (SMGL) in Uganda. Washington, DC: Futures Group, Health Policy Project; 2013.

35. Futures Group. Expenditure Analysis for Saving Mothers, Giving Life (SMGL) in Zambia. Washington, DC: Futures Group, Health Policy Project; 2013.

36. Baltussen R, Adam T, Tan-Torres Edejer T, et al. Part one: methods for generalized cost-effectiveness analysis. In: Tan-Torres Edejer T, Baltussen R, Adam T, et al., eds. WHO Guide to Cost-Effectiveness 
Analysis. Geneva, Switzerland: World Health Organization; 2003:1-122.

37. Bank of Uganda. Annual Report. Kampala, Uganda: Bank of Uganda; 2017.

38. Bank of Zambia. 2018. http://www.boz.zm/. Accessed May 29, 2018.

39. International Monetary Fund. World Economic Outlook Database, October 2017. https://www.imf.org/external/pubs/ft/weo/ 2017/02/weodata/index.aspx. Accessed January 2, 2018.

40. Hendriks ME, Kundu P, Boers AC, et al. Step-by-step guideline for disease-specific costing studies in low- and middle-income countries: a mixed methodology. Glob Health Action. 2014;7(1):23573. CrossRef. Medline

41. Musau S, Okello F, Kramer C. Costs of Healthy Baby Voucher Program Services. Bethesda, MD: Strengthening Health Outcomes through the Private Sector Project, Abt Associates Inc.; 2015.

42. WHO, UNICEF, UNFPA, World Bank Group, United Nations Population Division. Trends in Maternal Mortality: 1990 to 2015. Geneva: World Health Organization; 2015.

43. UN Inter-agency Group for Child Mortality Estimation. Child mortality estimates: neonatal mortality rate (NMR) and number of neonatal deaths. 2018. http://www.childmortality.org/. Accessed December $14,2018$.
44. World Health Organization. Global Health Observatory data repository life tables by country. Zambia. 2018. http://apps.who. int $/$ gho $/$ data $/$ ?theme=main\&vid=61850. Accessed May 30, 2018.

45. World Health Organization. Global Health Observatory data repository life tables by country. Uganda. 2018. http://apps. who int/gho/data/view.main.61730? lang=en. Accessed May 30, 2018

46. Terris-Prestholt F, Watson-Jones D, Mugeye K, et al. Is antenatal syphilis screening still cost effective in sub-Saharan Africa. Sex Transm Infect. 2003;79(5):375-381. CrossRef. Medline

47. Roberts G, Roberts C, Jamieson A, Grimes C, Conn G, Bleichrodt R. Surgery and obstetric care are highly cost-effective interventions in a sub-Saharan African district hospital: a three-month single-institution study of surgical costs and outcomes. World J Surg. 2016;40(1):1420. CrossRef. Medline

48. Bazile J, Rigodon J, Berman L, et al. Intergenerational impacts of maternal mortality: qualitative findings from rural Malawi. Reprod Health. 2015;12(Suppl 1):S1. CrossRef. Medline

49. Darroch JE. Adding It Up: Investing in Contraception and Maternal and Newborn Health, 2017-Estimation Methodology. New York: Guttmacher Institute; 2018.

50. Tagar E, Sundaram M, Condliffe K, et al. Multi-country analysis of treatment costs for HIV/AIDS (MATCH): facility-level ART unit cost analysis in Ethiopia, Malawi, Rwanda, South Africa and Zambia. PLoS One. 2014;9(11):e108304. CrossRef. Medline

\section{Peer Reviewed}

Received: August 21, 2018; Accepted: January 27, 2019

Cite this article as: Johns B, Hangoma P, Atuyambe L, Faye S, Tumwine M, Zulu C, et al; Saving Mothers, Giving Life Working Group. The costs and cost-effectiveness of a district strengthening strategy to mitigate the 3 delays to quality maternal health care: Results from Uganda and Zambia. Glob Health Sci Pract. 2019;7(suppl 1):S104-S122. https://doi.org/10.9745/GHSP-D-18-00429

(C) Johns et al. This is an open-access article distributed under the terms of the Creative Commons Attribution 4.0 International License (CC BY 4.0), which permits unrestricted use, distribution, and reproduction in any medium, provided the original author and source are properly cited. To view a copy of the license, visit http://creativecommons.org/licenses/by/4.0/. When linking to this article, please use the following permanent link: https:// doi.org/10.9745/GHSP-D-18-00429 